\title{
WALTER BENJAMIN E A AUTOBIOGRAFIA: UMA LEITURA DE “A IMAGEM DE PROUST"”
}

Sarah Diva da Silva Ipiranga

\begin{abstract}
RESUMO
Walter Benjamin, em seu texto "A imagem de Proust", tece inúmeras e importantes considerações acerca da autobiografia. Na medida em que analisa $\grave{A}$ la recherche du temps perdu, o pensador alemão pontua vários fatores que dariam corpo ao texto autobiográfico: a memória e suas categorias (reminiscência, esquecimento, memória involuntária, continuum da rememoração), como também visualiza os sentimentos que acionariam o fluxo rememorativo (a doença, o envelhecimento e a morte) e a consequência dessa fusão: a busca da felicidade e do rejuvenescimento. A partir dessas proposições, Benjamin dialoga com a tradição do pensamento filosófico que deposita sua reflexão nos móbiles da memória, como Henri Bergson e Gaston Bachelard. Este trabalho busca identificar tais pontos de contato e propor novas ligações com estudos específicos acerca dos chamados relatos de si, em que a autobiografia está incluída, com destaque para George Gusdorf e Paul de Man.
\end{abstract}

Palavras-chave: Memória. Autobiografia. Sonho. Estilo.

\section{WALTER BENJAMIN AND THE AUTOBIOGRAFY: A READING OF THE "THE IMAGE OF PROUST"}

\begin{abstract}
Walter Benjamin, in his text "The image of Proust", makes numerous and important considerations about the autobiography. In so far as he analyzes À la recherche du temps perdu, the German thinker points out several factors that would give substance to the autobiographic text: memory and its categories (reminiscences, forgetfulness, involuntary memory, the continnum of remembrance), as well as he visualizes the feelings that would activate the reminiscent flow (disease, aging and death) and the consequences of this merging: the pursuit for happiness and rejuvenation. From these propositions, Benjamin dialogues with the tradition of philosophical thought that puts its reflection in mobile memory, like Henri Bergson and Bachelard. This paper seeks to identify these contact points and propose new links with specific studies on the so-called reports of oneself, in which autobiography is included, especially in George Gusdorf and Paul de Man.
\end{abstract}

Keywords: Memory. Autobiography. Dream. Style.

Professora da Universidade Estadual do Ceará (UECE). Pós-Doutora em Literatura Comparada Universidade de Lisboa. Brasileira, residente em Fortaleza- CE. Email: sarah.diva@uece.br 
Walter Benjamin, em "A imagem de Proust" (BENJAMIN, 2012, 37-50), oferece-nos uma leitura instigante acerca dos mecanismos que cercam o texto literário confessional. Seu objetivo não é fazer um tratado sobre a autobiografia, mas sim analisar o texto proustiano por esse viés, observando delicadamente como as camadas de memória se depositam sobre a linguagem e quais as consequências disso para a estrutura discursiva. Na medida em que analisa $\dot{A}$ la recherche $d u$ temps perdu ${ }^{1}$, de Marcel Proust, o pensador alemão, da forma como lhe é peculiar (circular e pouco dogmática), vai, aos poucos, tocando numa série de questões que são pertinentes ao texto autobiográfico. Entre os vários apontamentos sobre os quais discorre, podemos entrever claramente categorias e classificações que são comumente abordadas por vários autores que formam a tradição de estudo deste gênero (cuja nomeação mais comum é "escrita do eu"): as relações entre narrativa memorialística e estilo, a força e métodos da rememoração, os tipos de memória envolvida neste processo (voluntária e involuntária) etc. Seu trabalho investigativo, assim, debruça-se sobre a 'máquina' das lembranças proustianas, como também investe nos sentimentos que são o motor da rememoração (a doença, o envelhecimento e a morte) e os objetivos que atravessam essa escrita especular (a busca da felicidade e do rejuvenescimento).

A partir da leitura que propõe para a obra do escritor francês, Benjamin dialoga, mesmo que de forma não intencional, com uma linhagem filosófica que elegeu a memória como um foco central das suas reflexões. Falamos aqui, em princípio, de Henri Bergson e Gaston Bachelard, cujos livros, respectivamente, Matéria e memória (2010) e A poética do devaneio (2006), são análises densas sobre os processos rememorativos. Da mesma maneira, seu texto também antecipa conceitos delimitados futuramente pela teoria literária, sobretudo os estudos acerca dos chamados relatos de si ou escrita do eu, com destaque para George Gusdorf e Paul de Man, o que atesta a inventividade e perspicácia benjaminiana.

Sabe-se que a obra se compõe, na verdade, de sete livros. No Brasil foi publicada pela editora Globo (No caminho de Swann saiu em 1948) e contou com a participação de tradutores como Manuel Bandeira e Mário Quintana, entre outros. Em 2006, a editora preparou uma reedição cuidadosa, que teve a contribuição de Olgária Matos, Guilherme Ignácio da Silva e Jeanne-Marie Gagnebin. 
Esse trabalho procura fazer uma aproximação entre as ideias de Walter Benjamin sobre a especificidade dos escritos autobiográficos e as reflexões, igualmente delimitadas acerca do tema, dos autores citados anteriormente. O movimento da análise centrará seu exame no papel da memória e da escrita na constituição literária dos relatos. Para tanto, inicialmente faremos uma leitura contrastiva e, aos poucos, aprofundaremos as questões postas pelos pensadores. Como o texto de Benjamin aqui estudado tem origem, motivo e realização na literatura (À la recherche du temps perdu), optamos por finalizar nosso trabalho com a inclusão de um novo tecido literário, a saber, a poesia da portuguesa Teresa Rita Lopes. Mais conhecida por seu trabalho exaustivo sobre Fernando Pessoa ${ }^{2}$, ela é, indiscutivelmente, uma voz que se destaca na seara poética lusófona com sua sonoridade ímpar, em cujos versos a memória dedilha uma dicção particular, melancólica. O livro selecionado, pelo próprio título, já indica a afinidade com o tempo benjaminiano: Os dedos, os dias, as palavras (1987).

\title{
1. As formas do lembrar: entre o sonho e o devaneio das palavras
}

Para analisar a obra de Marcel Proust, Benjamin vale-se de alguns conceitos que são preciosos para a compreensão de dois fenômenos essenciais na sua trajetória intelectual: esquecer e lembrar. Por meio de um jogo em que as duas ações movem-se entremeadas às e nas palavras, o filósofo procura associar a escrita autobiográfica proustiana ao trabalho da memória involuntária e esta, por sua vez, ao esquecimento.

\begin{abstract}
Não se encontra a memória involuntária de Proust muito mais próxima do esquecimento do que daquilo que chamamos em geral de rememoração? $\mathrm{E}$ não seria esse trabalho de reminiscência espontânea, em que a rememoração é a trama e o esquecimento a urdidura, muito antes o oposto do trabalho de Penélope, ao invés de sua cópia? (BENJAMIN, 2010, 38) (grifos nossos)
\end{abstract}

Para Benjamin, o acontecimento vivido precisa do esquecimento para ser rememorado; neste trajeto, que ele denomina de continuum da rememoração, a

2 São muitas as publicações de Lopes que tratam da poesia pessoana. Destacamos, no Brasil, uma antologia da Ed. Global, Os melhores poemas de Fernando Pessoa (2003), na qual a escritora portuguesa tanto empreende a seleção quanto prefacia. De sua lavra, merecem alusão Cicatriz (1997), Afectos (2000), A fímbria da fala (2002).

Professora da Universidade Estadual do Ceará (UECE). Pós-Doutora em Literatura Comparada Universidade de Lisboa. Brasileira, residente em Fortaleza- CE. Email: sarah.diva@uece.br 
memória urde as lembranças e propicia que elas se transformem em texto, num processo que se assemelha à visão de uma tapeçaria invertida. Se é a memória que comanda em princípio o disparo da escrita, há aquele momento em que o esforço da escrita sobrepõe-se à espontaneidade das lembranças e da escuridão dos sonhos emerge uma vontade e uma verdade.

Refletindo sobre o mesmo assunto e dedicando a ele um livro inteiro, Henri Bergson procura, já de forma dicotômica e científica, as formas e processos de estruturação e uso da memória. Seu trabalho investigativo intenta classificar os tipos de memória e nessa classificação encontramos uma contiguidade com o texto benjaminiano, a despeito da diferença de estilo e abordagem metodológica. Para o pensador suíço, o sistema da rememoração situa-se em uma divisão básica e preliminar para o campo operatório: memória hábito e memória espontânea. Centrado nessa dialética, ele procura compreender os processos e imagens que estão a ela associados.

\begin{abstract}
Digamos, portanto, para resumir o que precede, que o passado parece efetivamente armazenar-se, conforme havíamos previsto, sob essas duas formas extremas, de um lado os mecanismos motores que a utilizam, de outro as imagens-lembranças pessoais que desenham todos os acontecimentos dele com seu contorno, sua cor e seu lugar no tempo. [...] A primeira, conquistada pelo esforço, permanece sob a dependência da nossa vontade; a segunda, completamente espontânea, é tanto volúvel em reproduzir quanto fiel em conservar. (BERGSON, 2010, 97)
\end{abstract}

Sublinhemos os dois pontos destacados pelo pensador que parecem, a princípio, contrários: volúvel e fiel. A volubilidade da lembrança oferece a mobilidade que um esquecimento necessita; já a fidelidade, embora categoria fixa, evidencia a permanência na nossa mente de uma quantidade de lembranças que não poderíamos supor. Isso se dá em vista de que não há sedimento de memória; para Bergson as lembranças estão, na verdade, num circular contínuo e sua irrupção espontânea independe da nossa vontade. Para dar ideia de como se acomodam as imagens, ele assim nos diz: "Todas essas imagens agem e reagem umas sobre as outras em todas as suas partes elementares" (BERGSON, 2010, 11). A ideia de um baú ou caixa de guardados passa ao largo do pensamento bergsoniano. 
Bergson também enfatiza o potencial imaginativo que só a memória espontânea pode ter em contraposição à utilidade do hábito (memória aprendida). O hábito domina o adulto, a memória espontânea reside no sonho da infância:

\begin{abstract}
A diminuição aparente da memória, à medida que a inteligência se desenvolve, deve-se portanto à organização crescente das lembranças como ato. [...] Mas se nosso passado permanece quase inteiramente oculto para nós é porque é inibido pelas necessidades da ação presente, ele irá recuperar a força de transpor o limiar da consciência sempre que nos desinteressarmos da ação eficaz para nos recolarmos, de algum modo, na vida de sonho. (BERGSON, 2010, 180).
\end{abstract}

Benjamin vai tocar nessa 'noturnidade' das lembranças utilizando a metáfora do trabalho de Penélope, como referimos anteriormente. Segundo ele, a escritura é o inverso da tapeçaria da esposa de Ulisses, pois é o dia que destece o trabalho da noite, ou como Bergson afirma, a claridade denotativa dos fatos apaga o brilho noturno das lembranças. O esquecimento é que tece a tapeçaria da existência da vida e o hábito encobre a imaginação:

Em cada manhã, ao acordarmos, em geral fracos e apenas semiconscientes, seguramos em nossas mãos apenas algumas franjas da tapeçaria da existência vivida, tal como o esquecimento a teceu para nós. Mas cada dia, com suas ações intencionais e, mais ainda, com suas rememorações intencionais, desfaz os fios, os ornamentos do olvido (BENJAMIN, 2012, 38).

Neste momento não há como não relacionar as proposições acima ao pensamento de Gaston Bachelard. Sobretudo em A poética do devaneio, o filósofo sublinha intensamente o poder do sonho e do devaneio na força criadora do homem. Seus exemplos alinham-se aos de Benjamin e Bergson: "Para um sonho que se conta ao regressar à luz do dia, quantos sonhos cujo fio se perdeu" (BACHELARD, 2006, 141). Dentro desse fenômeno, ele indica subclasses, o devaneio, por exemplo, e é por esse caminho que seu espaço de reflexão se estrutura, com ênfase no papel da infância na duração e permanência do poético, o que também o aproxima do pensamento dos dois autores aqui analisados, posto que também 
privilegiam o fenômeno da infância como essencial ao processo criador e à manifestação do mais humano em nós. ${ }^{3}$

$\mathrm{Na}$ linguagem extremamente poética que o diferencia, Bachelard coloca a memória numa perspectiva de interação cósmica, do ser com as imagens que o fundam, daí a supremacia da infância. Para ele, existe uma memória pura, que também é chamada de inútil, como uma 'não-vida', um ócio do espírito (que poderíamos aqui relacionar à memória involuntária benjaminiana e à memórialembrança de Bergson). O tempo de Bachelard, por sua vez, escapa ao calendário oficial, e situa-se no que ele denomina de estações: "A lembrança pura não tem data. Tem uma estação. É a estação que constitui a marca fundamental das lembranças" (BACHELARD, 2006, 111) (grifo do autor). Assim, se para Bergson o hábito é o que nos afasta da possibilidade criadora, para Bachelard é a história que mitiga os sonhos do homem:

\begin{abstract}
Quanto mais mergulhamos no passado, mais aparece como indissolúvel o misto psicológico memória-imaginação. Se quisermos participar do existencialismo do poético, devemos reforçar a união da imaginação com a memória. Para isso é necessário desembaraçar-nos da memória historiadora, que impõe os seus privilégios ideativos. Não é uma memória viva aquela que corre pela escala das datas sem demorar-se o suficiente nos sítios da lembrança (BACHELARD, 2006, 114).
\end{abstract}

Percebemos, portanto, que a memória tem várias formas de ação sobre o pensamento e a experiência. Em cada um dos filósofos, ela possui, entretanto, modos de manifestação e realização diversos. Bergson pondera sobre as formas de resgatar as lembranças e "construir um mecanismo estável que a [imagem] substitua" (BERGSON, 2010, 93). O filósofo suíço, no entanto, não explora o papel dos mecanismos da escrita literária dentro desse processo complexo que estabiliza as "imagens de sonho" e prefere circunscrever suas reflexões a exemplos do cotidiano. Procura na exemplaridade das ações concretas (comportamento dos animais, os processos de guardar os ensinamentos de uma lição etc.) a validação de suas ideias ("Os fatos confirmam a hipótese?" é sua pergunta mais constante) 4 .

3 De Benjamin é inevitável citar O brinquedo, a criança e a educação (1984) e sua última publicação no Brasil $A$ hora das crianças: narrativas radiofônicas (2015).

4 Bachelard não the perdoa o afinco cientificista e assim se exprime sobre o modelo de pensamento bergsoniano: "Em Bergson parece que as lembranças puras são imagens em moldura. Por que

Professora da Universidade Estadual do Ceará (UECE). Pós-Doutora em Literatura Comparada Universidade de Lisboa. Brasileira, residente em Fortaleza- CE. Email: sarah.diva@uece.br 
Nesse aspecto, o pensamento de Bachelard afina-se mais com 0 de Benjamin, pois ambos colocam constantemente o texto literário no centro de suas conjecturas (o livro de Bachelard está repleto de versos; Benjamin dedicou boa parte de sua obra à literatura e aos escritores). No entanto, apesar das diferenças epistemológicas e metodológicas, os três pensadores afirmam uma memória diferenciada, oculta, poderosa, notívaga, centrada na dissipação do concreto e do presente. E aqui retomamos o texto sobre Proust para recolocar essa questão. Ao depositar sobre o discurso proustiano a capacidade de reinventar a noite ("Pois aqui é o dia que desfaz o trabalho da noite"), Benjamin dedica-se a perscrutar os passos proustianos que levam para o dia os sonhos e devaneios da noite de lembranças: "Foi por isso que Proust transformou, ao final, seus dias em noites para dedicar todas as suas horas ao trabalho, sem ser perturbado, no quarto escuro, sob uma luz artificial..." (BENJAMIN, 2012, 38). No afã de não perder todas as franjas do tecido da lembrança, ele aproveita o tempo desperto do dia para capturar, com o esforço de que falava Bergson, as imagens bachelardianas. Na sua 'floresta encantada da rememoração', Proust avidamente detém-se em todos os movimentos que dão ritmo ao cotidiano sem deixar que eles percam o devaneio que Ihes deu origem. Assim, peremptoriamente, Walter Benjamin afirma: "Toda interpretação sintética de Proust deve ligar-se ao sonho" (BENJAMIN, 2012, 40).

A partir do exposto, podemos introduzir questões mais específicas que liguem o relembrar ao ato da escrita.

\subsection{Entre viver e narrar: o texto}

Em meio às diversas abordagens que faz acerca da memória, Benjamin articula-as às questões específicas do texto literário e envereda por uma leitura que não desconsidera aspectos estilísticos e estruturais ou relativos ao gênero. Sobre $\dot{A}$ la recherche du temps perdu enquanto obra, afirma que é difícil classificá-la porque "conjuga a poesia, a memorialística e o comentário". Nesse mesmo raciocínio, relaciona, intuitivamente, tal conjugação de gêneros num mesmo livro à 'síntese impossível' que a autobiografia provoca: "a absorção do místico, a arte do prosador,

lembraríamos de ter aprendido uma lição sobre o banco de um jardim? [...] Por uma fatalidade da época, ele acredita no fato psíquico e sua doutrina da memória permanece, no fim das contas, como uma doutrina da memória" (BACHELARD, 2006, p. 110). 
a verve do autor satírico, o saber do erudito e a concentração do monomaníaco..." (BENJAMIN, 2012, 37). São muitos eus, com expressões diversas, que se manifestam e elaboram a subjetividade das lembranças. Assim, todos os gêneros estão contidos na autobiografia. Como veremos adiante, a convergência de tantos saberes e estilos têm a ver com o processo de rememoração e à infinitude que é a marca do lembrar. Por enquanto, começaremos nossa escuta a partir da marcação do gênero.

Ao formular essas prerrogativas, Benjamin consequentemente chama a atenção para a construção do conceito e da classificação dos textos autobiográficos em relação aos outros gêneros. Para que essa indagação fique mais clara, vamos agora nos reportar, de forma introdutória, à tradição de estudos que versa sobre essa questão.

George Gusdorf é exemplo de um pensador que procurou delimitar as vias que conformam a autobiografia, traçando este caminho desde a Antiguidade Clássica, seus antepassados, inspiração, influências, passando pela exemplaridade das obras de Santo Agostinho e Rousseau, como textos sistematizados em torno da escrita do eu, até escritos mais contemporâneos.

\footnotetext{
La autobiografia es un género firmemente estabelecido, cuya historia se presenta jalonada de una serie de obras maestras, desde las Confessiones de san Agustín hasta Si le grand meurt de Gide, passando por las Confessiones de Rousseau, Poesía y verdade, las Memorias de ultratumba o la Apología de Newman. (GUSDORF, 1991, 9)
}

Não cabe aqui uma extensa revisão histórica do tema, mas é bom salientar que Santo Agostinho e Rousseau são comumente considerados os dois autores que organizaram o campo semântico da autobiografia, colocando a consciência de si como centro das reflexões. O primeiro ainda mantém seu texto sob a guarda da religião, por isso a confissão e as relembranças estão no setor da utilidade (salvação divina) e não do motivo em si da escrita. Já Rousseau, desimpedido da conversão, traz a maturidade literária que as confissões exigiam, aliando estilo, recordação e eu biográfico ${ }^{5}$.

5 Sobre Rousseau, ver Jean-Jacques Rousseau: a transparência e o obstáculo (1991), de Jean Starobinski, especificamente o capítulo 7: "Os problemas da autobiografia". 
O que se verifica, sobretudo nos séculos posteriores ao lluminismo, é a consolidação do gênero: "La aparición de la autobiografia supone uma nueva revolucíon espiritual: el artista y el modelo coinciden..." (GUSDORF, 1991, 10) A parir daí a reflexão teórica vai se preocupar em classificar os diversos discursos (diários, cartas, autorretrato, romance autobiográfico, memórias etc.), dando por certo a inclusão do gênero na tradição literária.

El autor de un diário íntimo, anotando día a día sus impressiones y sus estados de ánimo, fija el cuadro de su realid cotidiana sin preocupación alguna por la continuidade. La autobiografía, al contrario, exige que el hombre se sitúe a cierta distancia de sí mesmo, a fin de reconstiuirse en su unidad y en su identidade a través del tempo. (GUSDORF, 1991,12)

A discussão proposta por Benjamin, entretanto, descola-se dessa categorização, pois para ele é fácil conviver com a manifestação de vários gêneros num só e trata de investigar o porquê do trabalho inventariante da memória literária. Para dialogar com essa perspectiva, é preciso trazer para a discussão o teórico literário belga Paul de Man $^{6}$ e especificamente seu texto "Autobiografia como desfiguração" (1984). Man enfrenta o problema do gênero ao evitar as classificações internas e históricas. De princípio, apreende-se do texto uma certa má vontade com a autobiografia na medida em que procura situá-la entre os vários discursos que compõem o literário, com desvantagem clara para ela na comparação: "Transformar a autobiografia em um gênero a eleva acima do status literário de mera reportagem, crônica ou memória e lhe confere um lugar, ainda que modesto, entre as hierarquias canônicas dos maiores gêneros literários" (MAN, 1984, 67). Cita a excessiva publicação de textos autobiográficos como mais um problema que esse discurso tem a enfrentar. Segundo ele, o excesso de textos de fundo confessional, que têm em

6 Desconhecido no Brasil, a não ser pelo artigo que sublinhamos, Paul de Man foi um professor com atuação acadêmica de destaque nos Estados Unidos. Em português, encontramos algumas obras suas, a maioria em sebos: Alegorias da leitura (Imago, 1996); A resistência à teoria (ED. 70, 1989) e $O$ ponto de vista da cegueira, no qual dedica um capítulo a Proust (Angelus Novus, Cotovia, 1999). Após sua morte, a descoberta de artigos seus publicados em jornais colaboracionistas da Bélgica, alguns com conteúdo anti-semita, provocou um afastamento de seus livros e, consequentemente, um certo ostracismo. 
Proust o grande mestre ${ }^{7}$, enfraquece 0 gênero, pois há um excesso de história e uma exiguidade de estética.

Apesar dessa colocação que apela para outros fatores que não dizem respeito ao gênero em si (o narcisismo que acompanha a avalanche de biografias e

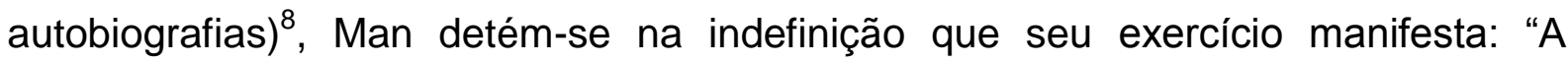
autobiografia se presta mal a uma definição genérica, cada exemplo específico parece ser uma exceção à norma" (MAN, 1984, 67). Como é a vida que gera a autobiografia, delimitá-la é impreciso. Essa instabilidade "desfaz o modelo tão logo ele é estabelecido". Ou seja, toda obra pode ser autobiográfica e uma definição estreita de suas qualidades é uma discussão menor.

Mais preocupado com as referências a que o escritor conduz, se reais ou ficcionais, ele anula este par aparentemente contraditório e diz que a referência histórica, ao virar lembrança e texto, transforma-se em figura, em ficção. A ficção beira o sonho e não precisa de comprovação. Portanto ilude-se quem acha que a autobiografia é mais realista e verdadeira que uma biografia. $O$ fato de o narrador contar sua própria história não o destitui do lugar de sonhador e da imprecisão de suas próprias lembranças. Por isso conclui:

\footnotetext{
O interesse da autobiografia, portanto, não está na revelação de um conhecimento confiável de si mesmo - ela não o faz - e sim na demonstração, de modo surpreendente, da impossibilidade de fechamento e de totalização de todos os sistemas textuais conformados por substituições tropológicas. (MAN, 1984, 70)
}

Man, que escolhe para análise os Essays upon Epitaphs, de Wordsworth, só inicia sua análise após colocar em destaque a descompressão que o fundo confessional imprime ao texto. A leitura que propõe é complexa, mas parte do pressuposto do texto autobiográfico como autorreparação e investiga como morte e vida se equilibram na feitura do trabalho artístico.

Assim, o que aproxima Benjanin e Paul de Man é o afastamento da necessidade de incluir a obra em uma tradição e a observação sensata de que cada lembrança gera uma escrita e, como são muitas as memórias, muitas serão as

7 Benjamin pontifica a escrita de Proust e sua importância: "Somente Proust fez do século XIX um século digno de memórias".

8 Ver sobre esse aspecto o excelente livro Máscaras de Narciso (1992), de Clara Rocha.

Professora da Universidade Estadual do Ceará (UECE). Pós-Doutora em Literatura Comparada Universidade de Lisboa. Brasileira, residente em Fortaleza- CE. Email: sarah.diva@uece.br 
formas de expressá-las. Se há vários tipos de lembrança, haverá vários modelos de textos autobiográficos (prosa, poesia, cartas). Segundo Benjamin, é a recordação em si e não o texto ou o binômio autor/texto que comanda e produz a estrutura e o significado da obra. Ou seja, o fato vivido é finito, mas a memória é aberta e ampla, cheia de possibilidades que são encaminhadas pelo fluxo das lembranças: "Um acontecimento vivido é finito, ou pelo menos encerrado na esfera do vivido, ao passo que o acontecimento rememorado é sem limites, pois é apenas uma chave para tudo que veio antes ou depois" (BENJAMIN, 2012, 38). Essa seria a principal consideração que ele apresenta concernente a uma categorização do texto autobiográfico e que é extremamente inovadora: "a unidade do texto está apenas no acto purus da própria rememoração, e não na pessoa do autor, e muito menos na ação" (BENJAMIN, 2012, 39) (grifo nosso).

Quanto a esta última observação, Man poderia redarguir ao colocar na linguagem a força de organização das memórias. De acordo com ele, o momento especular (o sujeito que ao contar precisa olhar para si) não é "primordialmente uma situação ou um evento que pode ser localizado em uma história, mas que é a manifestação, no nível do referente, de uma estrutura linguística" (MAN, 1984, 70).

Outro aspecto importante a analisar é o do papel do tempo na inscrição poética das lembranças. Benjamin atenta bem para esse aspecto, tão amplamente discutido na autobiografia, sobre a passagem das lembranças para o registro escrito e da função do tempo na sua transformação: "Sabemos que Proust não descreveu em sua obra uma vida como ela foi de fato, e sim uma vida rememorada por quem a viveu" (BENJAMIN, 2012, 38). Mais à frente adverte: "Pois o principal, para o autor que rememora, não é absolutamente o que ele viveu, mas o tecido da sua rememoração..."(BENJAMIN, 2012, 38). A observação, brilhante, mais uma vez, descentra a discussão dos pares antonímicos (realidade - ficção) que norteiam uma boa parte da pesquisa autobiográfica, preocupada em estabelecer claramente os limites entre o histórico, o pessoal e o imaginativo. O termo autenticidade aparece diversas vezes em textos seminais dos estudos autobiográficos - "La autenticidade" (GUSDORF, 2012, 18-48) - e através dele busca-se a verdade de um eu que sabemos incompleto o bastante para dominar as verdades. Benjamin subtrai essa preocupação, pois vê a vida como uma teia enredada pelo tempo, que dissolve as 
categorias anteriores e cria uma terceira, onde o que interessa é a verdade criada pelo texto e não a que estaria anterior a ele. Num bloco único - memória, sujeito, escrita - ele mergulha sua investigação e traz à tona um corpo no qual não podemos esquadrinhar as partes e sim apreciá-las em sua dança.

Sabemos que a comparação foi introdutória e haveria muito a discutir sobre as ideias postas pelos autores aqui citados. Porém nosso objetivo é dar sequência à discussão da condição do autobiográfico e agora expor uma realização contemporânea que toque na pele das lembranças e traga novamente para o papel as inquietações do eu das memórias. E será essa última categoria, o tempo, que vai nos aproximar da escrita poética de Teresa Rita Lopes.

\title{
1.3À procura do corpo da memória
}

A ação do tempo transforma-se em matéria poética nos escritos de Teresa Rita Lopes. Em Os dias os dedos as palavras (LOPES, 1987), parece que estamos imersos no vento das lembranças e somos levados por ele. Não há um momento específico (nascimento, parentes, brincadeiras, traumas, cidades) a recordar (isso acontecerá primorosamente no livro Cicatriz, de 1997), mas tão somente a existência suspensa na temporalidade e por ela impulsionada. A nomeação das partes do livro anuncia com delicadeza isso: "Antes de adverbialmente", "Já agora", "Os dias quietos", "Os dias adiados", "Os dias recuperados", "Os dias espaçosos", "Os dias custosos", "Assim como assim" etc.

Em "Arte poética I" (LOPES, 1987, 106), seguindo a tradição da ars, da qual Horácio é o grande exemplo, ela ressignifica o ato da poesia como um recordar marinho que encontra no corpo e nas palavras a sua forma de realização:

\author{
Dar \\ ao poema \\ a forma \\ o feitio \\ o único \\ certo \\ feitio
}

com que do fundo

do mar

Professora da Universidade Estadual do Ceará (UECE). Pós-Doutora em Literatura Comparada Universidade de Lisboa. Brasileira, residente em Fortaleza- CE. Email: sarah.diva@uece.br 


$$
\begin{gathered}
\text { foi expulsado } \\
\text { seixo, tronco } \\
\text { osso } \\
\text { lenho } \\
\text { arrebatado } \\
\text { noutra idade } \\
\text { agora } \\
\text { mansa } \\
\text { violentamente } \\
\text { restituído } \\
\text { à praia } \\
\text { ao litoral } \\
\text { de mim }
\end{gathered}
$$

Nascida em Faro, litoral ao Sul de Portugal, Lopes guarda em sua reminiscência as imagens marinhas que fundaram sua existência. Por isso, percebese que o agrupamento semântico está situado neste campo lexical (mar) e é através dele que a continuidade poética é montada. O voltar a si, marca da escrita confessional, encontra no oceano o espaço biográfico onde ele pode desaguar. tempo funciona como as ondas e os objetos, que elas tragam e devolvem à praia, as lembranças.

O imaginário das idades também aparece evidenciando um tempo cíclico, pois na velhice ("a idade mansa") volta-se à infância, ou a bem antes disso, e a escrita tenta dar movimento e visibilidade a esse processo. O mar, metáfora poderosa da instância temporal, devolve à velhice as partes de si que ficaram entregues ao mundo.

Obviamente não há uma idade fixa para a autobiografia, mas sabemos que o transcorrer do tempo é indispensável à formação da memória. Por isso, um amadurecimento é necessário para se ter a distância que o rememorar exige, ou seja, é essencial esquecer ${ }^{9}$. Segundo Benjamin é exatamente o entrecruzamento entre rememoração e velhice que nos permite a aproximação do texto proustiano.

9 Paula Morão, professora e pesquisadora portuguesa que há anos dedica seus estudos à autobiografia, confirma esse apontamento: “(...) um sujeito enfim maduro olha para sua própria imagem em contexto e em visão retrospectiva. Memorialismo e autobiografia tocam-se e cruzamse, na composição do retrato crítico de um 'eu' que se reconstitui e se situa no quadro complexo de um percurso no tempo e no espaço" (p. 15), (grifo nosso) (1993). 
De acordo com seu pensamento, a consciência de estar velho e da irreversibilidade desta condição traz para o escritor um mar de memória involuntária que dará sedimento ao escrito. Tal ação conduz ao rejuvenescimento: "É esta a obra da mémoire involontaire, da força rejuvenescedora capaz de enfrentar o inevitável envelhecimento" (BENJAMIN, 2010, 47).

Temos consciência que Benjamin, em "A imagem de Proust", analisa uma obra monumental, diversa radicalmente, pelo menos em número de páginas, do espírito recôndito, de concha do mar, que a poesia tem. Mas como uma concha reverbera o murmúrio do mundo, acreditamos que podemos fazer essa inter-relação. Além do mais, a leitura benjaminiana atenta aos detalhes que podem parecer insignificantes, mínimos da obra de Proust. Essa 'contra-leitura' está insuflada por uma sensibilidade que descobre no texto literário muito mais do que a história tem para contar. Talvez esteja em busca do que ela esconda: "Seria lícito dizer que todas as vidas, obras e ações importantes nada mais são que o desdobramento imperturbável da hora mais banal e mais efêmera, mais sentimental e mais frágil, da vida daquele a quem pertencem?" (BENJAMIN, 2010, 39) O efêmero, o frágil e o sentimental nos devolvem a outra dimensão do recordar. Nessa perspectiva, mais forte que os acontecimentos é a "realidade frágil e preciosa" da imagem.

No poema de Lopes, identificamos essa 'realidade frágil e preciosa' das imagens nos restos que o mar traz para a praia: "seixo, osso, lenho...". Nada de muito notável, monumental ou histórico, tão somente pedaços e sobras de uma existência que, pela maré do tempo, retornam ao eu, litoral de si mesmo. A poesia, pela condensação, acede, portanto, às imagens e nelas derrama sua historicidade. Ao contrário da prosa, que tem a seu favor o número de páginas, a denotação e a referencialidade que montam um discurso sequenciado, no texto poético os significados se acumulam e ocupam o mesmo espaço. Daí a depuração que as imagens propiciam: através da figuração, metafórica ou metonímica, elas fazem a linguagem dobrar-se sobre si mesma e atar uma ligação direta com as lembranças.

São as imagens, como diria Bergson, que irão consubstanciar memória e linguagem e não necessariamente a representação, motor maior da prosa: "Meu corpo é portanto, no conjunto do mundo material, uma imagem que atua como as outras imagens, recebendo e devolvendo movimento, com a única diferença, talvez, 
de que meu corpo parece escolher, em uma certa medida, a maneira de devolver o que recebe".(BERGSON, 2010, 14).

Vejamos agora mais dos poemas, chamados Ciclo 1 e 2 , nos quais as imagens são mais expandidas.

\author{
Ciclo 1 \\ Reencontro \\ o sabor \\ de um gesto \\ antigo \\ guardado \\ intacto \\ numa ruga \\ da memória \\ dos músculos \\ numa esquina \\ do correr \\ do sangue \\ acalentado \\ tão no cerne \\ dos meus ossos \\ aflorado \\ súbito \\ ao de cima \\ recém-chegado \\ de outra idade \\ de outro corpo \\ de mim \\ recuperado \\ de repente \\ filho pródigo
}

As metáforas aqui encontram uma centralidade no próprio corpo, 'armazém' das lembranças. Mais uma vez a ênfase está no mínimo, no detalhe, na delicadeza de uma percepção interna. Há claramente a ideia de um reencontro consigo, pois o crescimento, na maioria das vezes, nos aparta de nós mesmos, influenciados que estamos pelas premências do mundo. A irrupção do 'gesto antigo' para o tempo 
corrido traz para o eu o tempo de si, que agora ele vê guardado em seu próprio corpo. Os órgãos corporais são o depositário das lembranças e sua disposição toma a feição de um caminho percorrido pelas recordações ("esquina do correr do sangue"). Assim, nada tem cheiro de guardado, pois tudo estava protegido pela vida dos ossos, da carne, dos músculos, do sangue. Dessa vida inconsciente, as lembranças sobem à consciência (processo por demais descrito por Bergson), 'afloram ao de cima', trazendo consigo partes de outro tempo, de um outro sujeito.

A imagem de um eu duplicado, que funda a autobiografia, está bem nítida no poema. Tal descolamento é essencial à prática da rememoração, pois a compreensão dessa duplicidade é que permite a arguição de si. Paul de Man enfatiza o momento especular, de desdobramento do sujeito, como fundador da prática autobiográfica: "Essa estrutura especular é interiorizada em um texto no qual o autor declara ser ele o sujeito do seu entendimento" (MAN, 1984, 70). Tal afirmação conjuga-se com o que foi dito anteriormente, pois será a velhice que permitirá esse desdobramento do indivíduo e o retorno da consciência.

Em "Ciclo 2" (LOPES, 1987, 116), a reflexão poética tem sequência e acrescenta outras imagens. De certa forma, duas forças entram em ação na hora de recordar: uma centrípeta e outra centrífuga ${ }^{10}$.

\author{
De repente \\ o gesto mínimo \\ por onde \\ em nosso corpo \\ somos nós \\ Reencontrar \\ debaixo da pele \\ do tempo \\ essa coisa \\ única \\ mínima \\ que somos \\ que possuiu \\ outros lugares \\ que ocupou
}

10 Para ver, com clareza, o significado desses dois movimentos, indica-se a leitura do primeiro capítulo do livro Máscaras de Narciso, de Clara Rocha (1992).

Professora da Universidade Estadual do Ceará (UECE). Pós-Doutora em Literatura Comparada Universidade de Lisboa. Brasileira, residente em Fortaleza- CE. Email: sarah.diva@uece.br 


$$
\begin{gathered}
\text { outro chão } \\
\text { que bebeu } \\
\text { outro ar } \\
\text { que palpou } \\
\text { outras coisas } \\
\text { que ficou } \\
\text { inalterável } \\
\text { no subterrâneo } \\
\text { mar } \\
\text { do corpo } \\
\text { que } \\
\text { de repente } \\
\text { aflora } \\
\text { irrompe } \\
\text { desabrocha } \\
\text { a cumprir } \\
\text { cósmicos } \\
\text { primordiais } \\
\text { caminhos } \\
\text { de água } \\
\text { e seiva } \\
\text { e fogo }
\end{gathered}
$$

Lopes agora acrescenta às imagens internas uma movimentação cósmica, numa sintonia que traz para o poema uma coexistência de temporalidades. O ser é habitado não só por um passado próprio, próximo, familiar, mas também por imagens que fazem uma ligação com o estar no mundo enquanto condição humana. Dessa forma, o poeta, ao conectar-se com suas recordações mais íntimas, por um movimento contíguo, aciona lembranças mais pretéritas, que estão incrustadas no seu corpo e que fazem falar outras vozes. A manutenção dessas imagens, além da seiva corporal, precisa dos caminhos da natureza (água, fogo), dos elementos que compõem o corpo do mundo, do qual não estamos apartados.

Estas últimas imagens do poema trazem-nos ao pensamento as reflexões de Bachelard acerca da relação do homem com as palavras: "Assim, palavras cósmicas, imagens cósmicas tecem vínculos do homem com 0 mundo".(BACHELARD, 2006, 181) Numa visão cíclica, imemorial do recordar, Bachelard credita à recordação um tempo que extrapola o próprio sujeito e mergulha numa transcendência temporal. A memória, então, conjuga-se ao movimento subterrâneo do homem na Terra, a um tempo mítico, ancestral: "Quem vai ao fundo 
do devaneio reencontra o devaneio natural, um devaneio do primeiro cosmos..." (BACHELARD, 2006, 180).

Vê-se, pela análise, que a escrita poética de Lopes funciona como uma autorreparação, para usar um termo de Man, e toca em tecidos corporais, cósmicos, intemporais. Para isso, é necessário "desalojar os pássaros noturnos”, como já havia percebido Benjamin. Aí o tempo adquire uma autonomia que liberta a escrita, o verso, o homem. Por isso, quando, no presente, se espera ansiosamente por algo que está para acontecer, diz-se comumente: "contando os dias nos dedos". No tempo poético, o contar desaparece e ficamos apenas com "os dedos os dias as palavras". 


\section{REFERÊNCIAS}

BACHELARD, Gaston. A poética do devaneio. Trad. Antônio de Pádua Danesi. 5. ed. São Paulo: Martins Fontes, 1988.

BENJAMIN, Walter. A imagem de Proust. In: Obras escolhidas I: Magia e técnica - Arte e política. Trad. Sérgio Paulo Rouanet. São Paulo: Brasiliense, 2012. p. 37-50.

BERGSON, Henri. Matéria e memória: ensaio sobre a relação do corpo com o espírito. Trad. Paulo Neves. 4. ed. São Paulo: Editora WMF Martins Fontes, 2010.

GUSDORF, Georges. Condiciones y límites de la autobiografía. Trad. Ángel G. Loureiro. Anthropos: la autobiografia y sus problemas teóricos: estúdios e investigación documental, Barcelona, n. 29, p. 9-18, 1991.

- La autenticidad. Trad. Dámaso Izuierdo Alegría. Rilce: Revista de Filología Hispánica. Navarra, n. 28.1, p. 18-48, 2012.

LOPES, Teresa Rita. Os dias, os dedos, as palavras. Porto: Ed. Figueirinhas, 1987.

Cicatriz. Lisboa: Ed. Presença, 1997.

Afectos. Lisboa: Ed. Presença, 2000.

A fímbria da fala. Vila Nova de Gaia: Ed. Ausência, 2002.

MAN, Paul de. Autobiografia como des-figuração. Disponível em: http://www.culturaebarbarie.org/sopro/outros/autobiografia.html\#texto1

MORÃO, Paula. Viagens na terra das palavras: ensaios sobre literatura portuguesa. Lisboa: Ed. Cosmos, 1993.

ROCHA, Clara. Máscaras de Narciso: estudos sobre a literatura autobiográfica em Portugal. Coimbra: Almedina, 1992. p. 9-56.

ROUSSEAU, Jean-Jacques. Confissões. Trad. José Benedicto Pinto e Raquel de Queiroz. São Paulo: Edipro, 2008.

SANTO AGOSTINHO. Confissões. Trad. J. Oliveira Santos e A. Ambrósio Pina. Petrópolis, RJ: Vozes, 2002.

STAROBINSKI, Jean. Os problemas da autobiografia. In: Jean-Jacques

Rousseau: a transparência e o obstáculo. Trad. Maria Lúcia Machado. São Paulo: Companhia das Letras, 1991. p. 187-207. 